\title{
Trilhas investigativas em educação estatística narradas por professores que ensinam matemática
}

\author{
Marcelo Bergamini Campos ${ }^{1}$
}

A obra Trilhas investigativas em educação estatística narradas por professores que ensinam matemática apresenta e discute seis projetos explorando conteúdos estatísticos que foram idealizados por professores do Ensino Fundamental. Os docentes socializam os avanços obtidos na condução destes trabalhos que tiveram caráter investigativo, possibilitando aos estudantes assumirem o papel de protagonistas na construção do conhecimento.

O livro é organizado pelas doutoras Celi Espasandin Lopes e Luzinete de Oliveira Mendonça, pesquisadoras que atuam no Programa de Pós-graduação em Ensino de Ciências e Matemática da Universidade Cruzeiro do Sul, com larga experiência na formação de professores e importantes investigações desenvolvidas na área de Educação Estatística. A obra não é estruturada em capítulos, como acontece de praxe, mas é apresentada em trilhas pedagógicas que, segundo as organizadoras, "se referem a caminhos percorridos por professores em suas escolas, decorrentes de suas práticas profissionais" (LOPES; MENDONÇA, 2017, p.11). Posterior à apresentação de cada uma destas trilhas, Lopes e Mendonça apresentam breves e profícuos textos que são denominados "Veredas" com o objetivo de analisar, a partir de uma consistente fundamentação teórica, cada um dos projetos narrados pelos professores.

A primeira trilha, intitulada "Seguindo a rota do atletismo e estatisticando nas aulas de matemática", é escrita por Adriana Franco de Camargo Augusto. Ela discute uma investigação realizada por alunos do nono ano do Ensino Fundamental envolvendo conteúdos estatísticos a partir de um projeto que teve por tema o atletismo.

Apesar da sugestão deste assunto não ter partido dos estudantes, mas da própria professora, é evidente a sua intenção de promover o protagonismo e a efetiva participação dos alunos nas etapas posteriores. Eles foram os responsáveis pela elaboração do questionário

\footnotetext{
${ }^{1}$ Escola Municipal Sebastião Francisco do Vale. Barbacena/MG. Endereço Eletrônico: marcelo.bergamini@hotmail.com Periódico Horizontes - USF - Itatiba, SP-Brasil - e019017
} 
utilizado nas entrevistas junto aos demais alunos da escola, bem como pela coleta, organização e interpretação dos dados.

A autora observa que, ao longo do projeto, os alunos tiveram a oportunidade de pesquisar e ampliar os conhecimentos sobre o atletismo e também acerca de recursos tecnológicos que permitem a produção de gráficos. A culminância do projeto, quando os estudantes apresentaram os resultados à comunidade escolar, é descrita como um momento importante e singular para todos.

A segunda trilha, apresentada com o título "Um atalho para uma boa escolha", é escrita por Rogério Ramos Socha. A gênese do projeto, que foi desenvolvido com alunos do oitavo ano do Ensino Fundamental, está associada a uma reportagem discutindo a interpretação frequentista da probabilidade. $\mathrm{O}$ autor percebeu as potencialidades da temática para uso em sala de aula tendo em vista que abordava a frequência com que jogadores de futebol direcionavam as cobranças de pênaltis a determinada posição do gol. Segundo a reportagem, dados estatísticos, obtidos a partir desta análise, seriam fundamentais nas tomadas de decisões de goleiros e, consequentemente, poderiam influenciar os resultados de algumas partidas realizadas em campeonatos.

A proposta de associar a abordagem de conteúdos estatísticos ao futebol veio ao encontro dos anseios do autor, que explicita o seu intento de desenvolver trabalhos diferenciados em sala de aula, explorando atividades relacionadas com o cotidiano e que possibilitam aos estudantes um maior envolvimento e interação.

Lopes e Mendonça observam que o trabalho realizado pelo professor possibilitou discussões probabilísticas a partir de dados produzidos pelos alunos. Por outro lado, ponderam que o desenvolvimento da proposta com fins didáticos não contribui com a coleta de uma quantidade maior de dados implicando, dessa forma, em uma menor confiabilidade nos resultados.

Nathalia Tornisiello Scarlassari é a autora da terceira trilha, intitulada "O trajeto das preferências musicais para desvendar a estatística". Ao relatar o projeto realizado com alunos

$$
\text { Periódico Horizontes - USF - Itatiba, SP-Brasil - e019017 }
$$


do oitavo ano do Ensino Fundamental, tece reflexões sobre a sua prática sinalizando inclusive a possibilidade de ter efetuado maiores intervenções.

O tema que norteou a elaboração do projeto, definido pelos próprios estudantes, envolveu a investigação sobre as preferências musicais da comunidade escolar. Eles delimitaram as variáveis relevantes para a pesquisa e elaboraram um questionário que foi respondido por seus familiares e pelos demais alunos da escola.

A autora destaca o envolvimento e satisfação dos estudantes na realização das diversas atividades. Apresenta tabelas e gráficos que foram elaborados a partir dos dados coletados e observa ainda que eles puderam constatar que algumas das crenças que manifestaram antes da realização da pesquisa foram desfeitas a partir da análise dos dados obtidos.

$\mathrm{Na}$ quarta trilha, Sandra Regina Aguiar Garcia apresenta o trabalho intitulado "Na trilha das medidas de tendência central com alunos de 6ㅇ ano". A autora discute a aplicação de tarefas que objetivavam facilitar a compreensão das noções de média, mediana e moda e que privilegiaram a exploração de medidas corpóreas que foram efetivadas pelos estudantes.

Ao apresentar e analisar produções escritas dos alunos, a autora pontua que eles nem sempre analisam a razoabilidade dos resultados encontrados, apresentando respostas que não são coerentes com a situação proposta. Tal constatação contribui para que ela reforce a defesa da necessidade de romper com práticas tradicionais de ensino, associadas fundamentalmente ao uso de técnicas, e buscar atividades contextualizadas que permitam aos estudantes construir os próprios conceitos e atribuir significados aos dados obtidos.

Vale destacar que o desenvolvimento do trabalho possibilitou aos estudantes explorar conteúdos matemáticos como as operações com números decimais e realizar diferentes tipos de medições, em alguns momentos fazendo o uso de fita métrica ou régua e, em outros recorrendo a unidades não padronizadas como, por exemplo, o palmo.

A quinta trilha, apresentada com o título "Vamos explorar o itinerário das brincadeiras preferidas?" é narrada por Sezilia Elizabete Rodrigues Garcia Olmo de Toledo e foi desenvolvida com alunos do quinto ano do Ensino Fundamental. O projeto envolveu as crianças na escolha da 
brincadeira de que mais gostam.

Na elaboração do gráfico a partir dos dados coletados, a autora aponta para algumas dificuldades que emergiram. No entanto, a estratégia utilizada merece destaque tendo em vista que possibilitou uma construção coletiva com a participação de todos os estudantes que puderam fazer sua própria representação no gráfico.

A última trilha, intitulada "Eu e o outro, o outro e eu, e os variados rumos que podemos percorrer juntos" é narrada por Solange Aparecida Corrêa e descreve um projeto desenvolvido com crianças do segundo ano do Ensino Fundamental. A autora demonstra nítida preocupação com a formação social e ética dos alunos e, dessa forma, traz para o contexto da sala de aula reflexões sobre temas como relações interpessoais, valorização do respeito às diferenças e a importância do cultivo de amizades.

Uma análise conjunta das seis trilhas apresentadas na obra, possibilita afirmar que elas compartilham diversas características. Com efeito, todas foram desenvolvidas por professores que ensinam Matemática no Ensino Fundamental junto aos seus próprios alunos e abordam conteúdos estatísticos. Há a preocupação dos autores em voltar o olhar aos reais interesses dos estudantes, desenvolvendo atividades associadas ao cotidiano e que sejam agradáveis e significativas.

As situações propostas podem ser também percebidas como desafiadoras na medida em que instigam os alunos a se engajarem na busca de estratégias para resolver os problemas emergentes. A condução dos trabalhos pelos professores, permitiu que os estudantes efetivamente se envolvessem nos projetos. Eles foram os protagonistas na elaboração dos questionários, organizaram e interpretaram os dados coletados que foram expostos em forma de gráficos e tabelas.

É conveniente destacar que os autores, ao relatarem as trilhas percorridas, não descrevem somente os êxitos no desenvolvimento do trabalho, demonstrando nítida preocupação em expor também as dificuldades e as limitações que surgiram, implicando, em alguns momentos, na necessidade de adequações nos projetos. Esta decisão confere maior 
autenticidade aos discursos e permite ao professor que optar por desenvolver a proposta constatar a relevância de considerar as peculiaridades do contexto em que está inserido e fazer os ajustes pertinentes.

Um olhar mais atento oportuniza constatar que estes professores manifestam a apreensão não somente com a formação matemática ou estatística de seus alunos, mas com a educação em um sentido mais amplo. Assim, em alguns momentos, percebem a possibilidade de proporcionarem aos estudantes o acesso a novas tecnologias, em outros, buscam abrir um espaço na sala de aula para a discussão de questões sociais almejando que eles se tornem efetivamente cidadãos que respeitam a si mesmos e aos outros.

Outro ponto saliente ao leitor é o sentimento de pertencimento a um grupo colaborativo que é manifestado por todos os autores. Trata-se do Grupo de Investigação e Formação em Educação Estatística (GIFEM), percebido por estes professores como um local essencial para o aprofundamento teórico e a troca de experiências. O desejo de romper com práticas tradicionais de ensino, manifestado nas narrativas dos trabalhos desenvolvidos, desafia e impulsiona os membros do grupo na busca de produzirem atividades diferenciadas a serem aplicadas em sala de aula, possibilitando aos discentes vivenciarem novas oportunidades de aprendizagem.

É importante frisar que o discurso dos autores encontra ressonância nas orientações presentes na Base Nacional Comum Curricular (BNCC). Ao discorrer sobre o trabalho com a estatística, o documento destaca a importância da abordagem de conceitos e procedimentos presentes no cotidiano, do uso de tecnologias e também o seu potencial diante da formação cidadã do educando. Com efeito, ao expor orientações sobre o trabalho com esta unidade temática, o documento observa que "todos os cidadãos precisam desenvolver habilidades para coletar, organizar, representar, interpretar e analisar dados em uma variedade de contextos, de maneira a fazer julgamentos bem fundamentados e tomar as decisões adequadas" (BRASIL, 2017, p. 272).

Finalmente, vale pontuar que a obra é apresentada em linguagem simples e objetiva permitindo ao leitor acompanhar o caminho percorrido pelos autores. De fato, conforme 
ressaltado no prefácio pelo Prof. Dr. Leandro de Oliveira Souza, os textos descrevem com naturalidade e com riqueza de detalhes trabalhos desenvolvidos no contexto escolar.

Estas considerações sugerem que a obra foi editada em um momento oportuno e que sua leitura assume grande importância para os agentes educacionais comprometidos com a formação dos educandos, de modo particular os professores que ensinam matemática na educação básica.

\section{Referências}

BRASIL. Ministério da Educação. Base nacional comum curricular. Brasília: MEC, 2017. Disponível em: http://basenacionalcomum.mec.gov.br/images/BNCC_20dez_site.pdf. Acesso em: 12 Jan. 2018.

LOPES, C. E.; MENDONÇA, L. O. (Orgs.) Trilhas investigativas em educação estatística narradas por professores que ensinam matemática. 1a ed. Campinas, SP: Mercado das Letras, 2017. (Série Educação Estatística)

Recebido em fevereiro de 2018.

Aprovado em maio de 2018. 